\title{
Overexpression of the structural maintenance of chromosome 4 protein is associated with tumor de-differentiation, advanced stage and vascular invasion of primary liver cancer
}

\author{
BO ZHOU, TAO YUAN, MENGGANG LIU, HONGMING LIU, JUN XIE, YANBIN SHEN and PING CHEN \\ Department of Hepatobiliary Surgery Daping Hospital and Research Institute of Surgery, \\ The Third Military Medical University, Chongqing, P.R. China
}

Received May 7, 2012; Accepted June 20, 2012

DOI: $10.3892 /$ or.2012.1929

\begin{abstract}
Structural maintenance of chromosome 4 (SMC4) is associated with tumorigenesis. The present study aimed at detecting SMC4 expression in primary liver cancer and its association with clinicopathological patient data. A total of 72 primary liver cancer tissues and 6 liver cell lines were assessed for expression of SMC4 mRNA and protein with qRT-PCR, western blotting and immunohistochemistry, respectively. SMC4 siRNAs were constructed to knockdown SMC4 expression, and phenotypic changes of hepatocellular carcinoma (HCC) cells were analyzed using flow cytometry and cell viability assays. The data showed that SMC4 mRNA and protein were highly expressed in HCC tissues compared to the normal tissues. Immunohistochemical analysis revealed that 52 of $72(72.2 \%)$ paraffin-embedded primary liver cancer tissues displayed strong cytoplasmic staining of SMC4 protein, whereas only $6(8.3 \%)$ normal liver tissues showed immunostaining of SMC4. Statistical analysis showed that SMC4 expression was significantly associated with tumor size, de-differentiation, advanced stages and vascular invasion of the primary liver cancers. Moreover, knockdown of SMC4 expression reduced HCC cell proliferation. These data demonstrated that expression of SMC4 protein may be useful for the early detection and prediction of primary liver cancer progression.
\end{abstract}

\section{Introduction}

Hepatocellular carcinoma (HCC) is one of the major global health problems. It accounts for $80-90 \%$ of primary liver cancers, is the fifth most common malignancy $(1,2)$, and the third most common cause of cancer-related death in the world $(3,4)$. The prognosis of primary liver cancer is very poor, as

Correspondence to: Dr Ping Chen, Department of Hepatobiliary Surgery Daping Hospital and Research Institute of Surgery, The Third Military Medical University, Chongqing, P.R. China

E-mail: chenpingsyd@126.com

Key words: structural maintenance of chromosome 4, biomarker, hepatocellular carcinoma, primary liver cancer evident by the fact that the number of annual deaths $(\sim 600,000)$ is almost equal to the number of new cases diagnosed annually. The median survival rates were $80 \%$ (range 63-97\%) at 1 year, $70 \%(34-78 \%)$ at 3 years and $50 \%(17-69 \%)$ at 5 years (5). To date, surgical resection is still the best option for treatment and cure of HCC. After resection, the 5-year survival rate of $\mathrm{HCC}$ reaches to $\sim 50 \%$ with the early disease, although these patients will have a high recurrence rate (6). However, only $<15 \%$ of the patients are eligible for surgery (7) because most are diagnosed at the advanced stages of the disease when the tumor has invaded and metastasized to other organs in the body. Most recently, other therapy choices have become available for treating or curing the primary liver cancer, such as liver transplantation (8), radiofrequency (9), chemoembolization (10), and gene and immune therapy (11); however, each treatment option has its own advantages and limitations. Thus, the early detection of primary liver cancer remains an important approach for prolonging the survival of patients (12), while cancer prevention may offer another possibility for reducing primary liver cancer incidence.

To this end, a number of biomarkers have been discovered during the past three decades, such as $\alpha$-fetoprotein [AFP; (13)], Des- $\gamma$-carboxy prothrombin (14), $\alpha$-l-fucosidase $(15,16)$, and glypican-3 [GPC-3; $(17,18)]$. Using these biomarkers, primary liver cancer can be diagnosed early. However, their sensitivity and specificity are still limited (e.g., the sensitivity of AFP for detecting early stage primary liver cancer is only between 30 and 60\%) (19-22). Although a combination of AFP with other biomarkers is able to improve early detection of primary liver cancer, the diagnostic accuracy for primary liver cancer is still low, especially with tumors $<3 \mathrm{~cm}$ in size (22-26). Therefore, their utility has been questioned, and many experts in the field consider them to be 'obsolete' (27). Thus, more reliable and useful biomarkers are urgently needed.

Our study focused on structural maintenance of chromosome 4 (SMC4) protein, which is a core subunit of condensin I and II, large protein complexes, involved in chromosome condensation. Previous studies have shown that SMC4 is a chromosomal ATPase that is highly conserved from bacteria to human, and plays a fundamental role in many aspects of higherorder chromosome organization and dynamics (28). Indeed, a previous study demonstrated that SMC4 protein might be useful 
in early detection of ovarian cancer (29), while another study showed that SMC4 regulated expression of the P53 pathway gene in breast cancer cells, which may be related to the changes in chromosome stability (30). However, the role and function of SMC4 in primary liver cancer remain unknown, this study aimed to determine expression of SMC4 mRNA and protein for association with clinicopathological feature of the primary liver cancer and then to investigate the role of SMC4 in primary liver cancer.

\section{Materials and methods}

Cell lines and culture. Human hepatocellular carcinoma Bel-7405, smmc-7721, and H7402 cell lines and human normal liver HL-7702, OSG-7701, and BH-HC1142 cell lines were purchased from Chinese Academy of Sciences (Shanghai, China). The normal cells HL-7702,OSG-7701, BH-HC1142 were used as controls. Cells were all grown in Dulbecco's modified Eagle's medium (DMEM; Invitrogen, Carlsbad, CA, USA) supplemented with $10 \%$ fetal bovine serum (Cyclone, Logan City, UT, USA) in a humidified incubator with $5 \% \mathrm{CO}_{2}$ at $37^{\circ} \mathrm{C}$.

Patients and tumor tissues. A total of 72 tissue samples from patients with primary liver cancer were obtained from Daping Hospital and Research Institute of Surgery, The Third Military Medical University between September 2009 and December 2010. The corresponding normal liver tissues were also collected from these patients and used as controls. These tissue specimens were immediately snap-frozen and kept at $-80^{\circ} \mathrm{C}$ until use. The patients were pathologically confirmed with primary liver cancer and no patients received chemotherapy or radiotherapy before surgery. This study was approved by the Ethics Committee of Daping Hospital and Research Institute of Surgery, the Third Military Medical University, Chongqing, China (no. ChiCTR-DDT-11001845), and all patients consented to participate in the study.

$R N A$ isolation and real-time reverse transcription-PCR. Total RNA was isolated from the tissues and cells using a TRIzol reagent (Invitrogen) according to the manufacturer's instructions. The isolated RNA was then pretreated with RNase-free DNase at $37^{\circ} \mathrm{C}$ for 30 min and then subjected to reverse transcription into cDNA by incubating $2 \mathrm{mg}$ RNA, $1 \mathrm{ml}$ oligo(dT), and $11 \mathrm{ml}$ DEPC-treated $\mathrm{H}_{2} \mathrm{O}$ at $70^{\circ} \mathrm{C}$ for $5 \mathrm{~min}$, followed by addition of $4 \mathrm{ml} 5 \mathrm{X}$ reaction buffer, $2 \mathrm{ml} \mathrm{dNTP} \mathrm{mixture,} 0.5 \mathrm{ml}$ ribonuclease inhibitor, and $1 \mathrm{ml}$ RevertAid ${ }^{\mathrm{TM}} \mathrm{M}$-MulV reverse transcriptase. The reaction was incubated at $42^{\circ} \mathrm{C}$ for $60 \mathrm{~min}$. For PCR amplification of SMC4 cDNA, SMC4 primers were first designed using the Primer Express software, version 2.0 (Applied Biosystems) and synthesized by GenePharma Co. (Shanghai, China) (Table I). PCR mixtures were then denatured at $95^{\circ} \mathrm{C}$ for $5 \mathrm{~min}$, followed by 40 cycles of $94^{\circ} \mathrm{C}$ for $20 \mathrm{sec}, 61^{\circ} \mathrm{C}$ for $20 \mathrm{sec}$, and $72^{\circ} \mathrm{C}$ for $20 \mathrm{sec}$, and a final extension at $72^{\circ} \mathrm{C}$ for $5 \mathrm{~min}$. Data were normalized to the geometric mean of the house-keeping gene, $\beta$-actin (Sangon Biotech, Shanghai, China) and expressed as the control.

Protein extraction and western blot analysis. For extraction of total cellular proteins from the tissues and cells, the samples were lysed and clarified by centrifugation in a RIPA buffer (Beyotime,
Shanghai, China). Next, $50 \mu \mathrm{g}$ of protein extracts were separated on $8 \%$ SDS-PAGE gels and electrophoretically transferred to nitrocellulose membranes at $100 \mathrm{~V}$ for $90 \mathrm{~min}$. The membranes were then blotted for 1-2 $\mathrm{h}$ with the following antibodies and dilutions: the goat anti-SMC4 polyclonal antibody at a dilution of 1:200 (Santa Cruz Biotechnologies, Santa Cruz, CA, USA), an anti-goat secondary antibody at a dilution of 1:400 (Santa Cruz Biotechnologies). The nitrocellulose membranes were incubated with ECL western blotting detection reagents from Beyotime and exposed to X-ray film to detect the positive protein band. $\beta$-actin (Santa Cruz Biotechnologies) was used as the control.

Immunohistochemistry. Immunohistochemical staining was performed to detect expression of SMC4 protein in primary liver cancer tissue specimens. Briefly, deparaffinized 5- $\mu \mathrm{m}$ paraffin sections were baked at $65^{\circ} \mathrm{C}$ for $30 \mathrm{~min}$, submerged in the ethylenediaminetetraacetic acid (EDTA) antigenic retrieval buffer, and microwaved for antigenic retrieval. After blocking non-specific binding with $20 \%$ normal serum in PBS for $1 \mathrm{~h}$, the sections were incubated with the goat anti-SMC4 polyclonal antibody at a 1:200 dilution (Santa Cruz Biotechnologies) overnight at $4^{\circ} \mathrm{C}$. The next day, the sections were washed three times with PBS and then incubated with anti-goat secondary antibody at a 1:400 dilution (Santa Cruz Biotechnologies), followed by further incubation with a streptavidin-horseradish peroxidase complex (Beyotime) for $30 \mathrm{~min}$ in the dark. Next, the sections were developed for color using DAB Plus as a chromogen. To quantify SMC4 protein expression, we used IHC score systems described previously (31). The intensity of SMC4 immunoreaction was scored as: 0 , negative; 1 , weak; 2 , moderate; and 3 , strong. The percentage of tumor cell stained were scored as 0 , negative; $1,<10 \%$ tumor cells stained; $2,10-50 \%$ tumor cells stained; and $3,>50 \%$ tumor cells stained. The staining intensity and percentage of staining were then multiplied to produce a SMC4 staining index, and the data ranged from 0 to 9. The expression levels of SMC4 were graded accorded to the following scoring criteria: grade 0 (score 0 ); grade 1 (scores 1-3); grade 2 (scores 4-6); and grade 3 (scores 7-9). Specimens with grade 1 were considered low expression, whereas grades 2 and 3 were defined as high expression.

Construction of SMC4 siRNA and transfection. To knockdown SMC4 expression, we first designed and synthesized 3 pairs of siRNA fragments and one pair of a negative control (Table II). We then chose a cell line with high SMC4 expression, H-7402, for SMC4 siRNA transfection. H-7402 cells were grown and SMC4 siRNA plus Lipofectamine 2000 were added to each well of cell cultures, and then kept in a $5 \% \mathrm{CO}_{2}, 37^{\circ} \mathrm{C}$ incubator for $72 \mathrm{~h}$. Next, real-time reverse transcription-PCR and western blotting were performed to analyze the reduced SMC4 expression before any other experiments were done.

Cell viability MTT assay. Cells were plated into a 96-well culture plate and kept in a $5 \% \mathrm{CO}_{2}, 37^{\circ} \mathrm{C}$ incubator for $24 \mathrm{~h}$. The next day, $50 \mu \mathrm{l}$ of $1 \mathrm{X}$ MTT was added to each cell culture well, incubated for $4 \mathrm{~h}$ at $37^{\circ} \mathrm{C}$, followed by addition of $150 \mu \mathrm{l}$ of dimethyl sulfoxide (DMSO). The optical density (OD) values of cell cultures were measured at a wavelength of $570 \mathrm{~nm}$ using an enzymelabeled instrument. Cell survival rate was then calculated as $\%=$ $\left(\mathrm{OD}_{\text {sample }}-\mathrm{OD}_{\text {blank }}\right) /\left(\mathrm{OD}_{\text {control }}-\mathrm{OD}_{\text {blank }}\right) \times 100 \%$. 
Table I. Primer sequences used qRT-PCR.

Forward primer

Reverse primer

\begin{tabular}{lll}
\hline SMC4 & 5'-GAGAAAATTCTGGGACCTTT-3' & 5'-TCTGAATGTCCTTGTGTTCA-3' \\
$\beta$-actin & 5'-CATTAAGGAGAAGCTGTGCT-3' & 5'-GTTGAAGGTAGTTTCGTGGA-3'
\end{tabular}

Table II. The sequences of SMC4 siRNA and negative control siRNA.

DNA sequences

\begin{tabular}{ll}
\hline Homo-2217 & 5'-GCCAAGAAUGUGUAAACUTT-3' \\
5'-AGUUUACACAUUCUUGGGCTT-3'
\end{tabular}

Homo-830

5'-GGCCUGCAGAGAUAAUACUTT-3' 5'-AGUAUUAUCUCUGCAGGCCTT-3'

Homo-1051 5'-GGCUAAAUGAACCUAUUAATT-3' 5'-UUAAUAGGUUCAUUUAGCCTT-3'

Negative

5'-UUC UCC GAA CGU GUC AGG UTT-3' 5'-ACG UGA CAC GUU CGG AGA ATT-3'

Statistical analysis. All statistical analyses were carried out using the SPSS 13.0 statistical software package (SPSS, Chicago, IL). The t-test was used to analyze the difference in SMC4 expression between normal and cancer tissues. The Mann-Whitney $\mathrm{U}$ test was performed to analyze the association between SMC4 expression and the clinicopathological data from the patients. $\mathrm{P}<0.05$ was considered statistically significant.

\section{Results}

Expression of SMC4 protein in hepatocellular carcinoma cell lines. In this study, we first detected expression of SMC4 mRNA and protein in HCC cell lines using qRT-PCR and western blot analyses, respectively, and found that SMC4 mRNA was highly expressed in HCC cell lines (i.e., Bel-7405, smmc-7721, and H7402) compared to normal cells (i.e., HL-7702, OSG-7701, and BH-HC1142; Fig. 1A). Similarly, the western blot data showed high expression of SMC4 in HCC cell lines (Fig. 1B).

Overexpression of SMC4 $\mathrm{mRNA}$ and protein in primary liver cancer tissues. Next, we detect SMC4 expression in primary liver cancer tissue samples using qRT-PCR and western blotting. The primary liver cancer tissues showed significantly higher levels of SMC4 mRNA than that of the paired normal liver tissues (Fig. 2A). Western blot analysis also showed that SMC4 protein was highly expressed in primary liver cancer tissues, whereas it was weakly detected in normal liver tissues (Fig. 2B). Furthermore, we performed immunohistochemistry, and the data shown in Fig. $2 \mathrm{C}$ revealed that strong SMC4 immunoreactions were detected in $52(72.2 \%)$ primary liver cancer tissue samples, weak immunoreactions detected in 16 (22.2\%) cases, and only 4 (5.9\%) cases with negative immunoreactions. In contrast, paired normal liver tissues only showed $6(8.3 \%)$ positive cases. The difference in SMC4 protein expressions between normal and cancer tissues was statistically significant ( $\mathrm{P}=0.000$ by Student's t-test).

Next, we associated SMC4 expression with clinicopathological data from primary liver cancer patients. The data are shown in Table III. We found a statistically significant association between SMC4 protein expression with tumor size $(\mathrm{P}=0.027)$, tumor differentiation $(\mathrm{P}=0.025)$, TNM stage $(\mathrm{P}=0.001)$, and vascular invasion $(\mathrm{P}=0.002)$; however, there was no association between SMC4 expression and the age and sex of patients
A

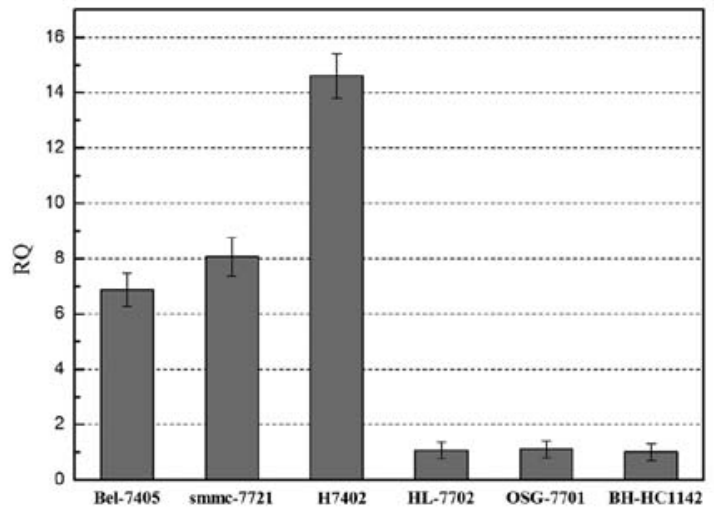

B

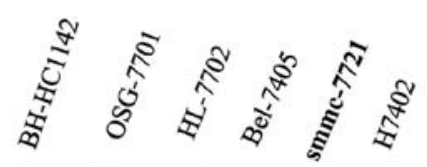

SMC4

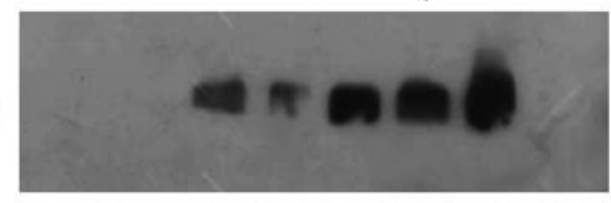

$\beta$-actin

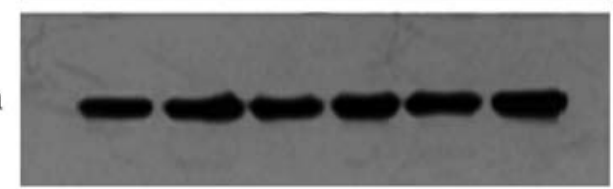

Figure 1. Analysis of SMC4 expression in hepatocellular carcinoma cell lines by real-time reverse transcription-PCR (A) and western blotting (B). (A) Expression of SMC4 mRNA in hepatocellular carcinoma cell lines (Bel-7405, smmc-7721, and H-7402) and human liver cell lines (HL-7702, OSG-7701, and BH-HC1142). (B) Expression of SMC4 protein in human liver cell lines (BH-HC1142, OSG-7701 and HL-7702) and hepatocellular carcinoma cell lines (Bel-7405, smmc-7721, and $\mathrm{H}-7402$ ). 
A
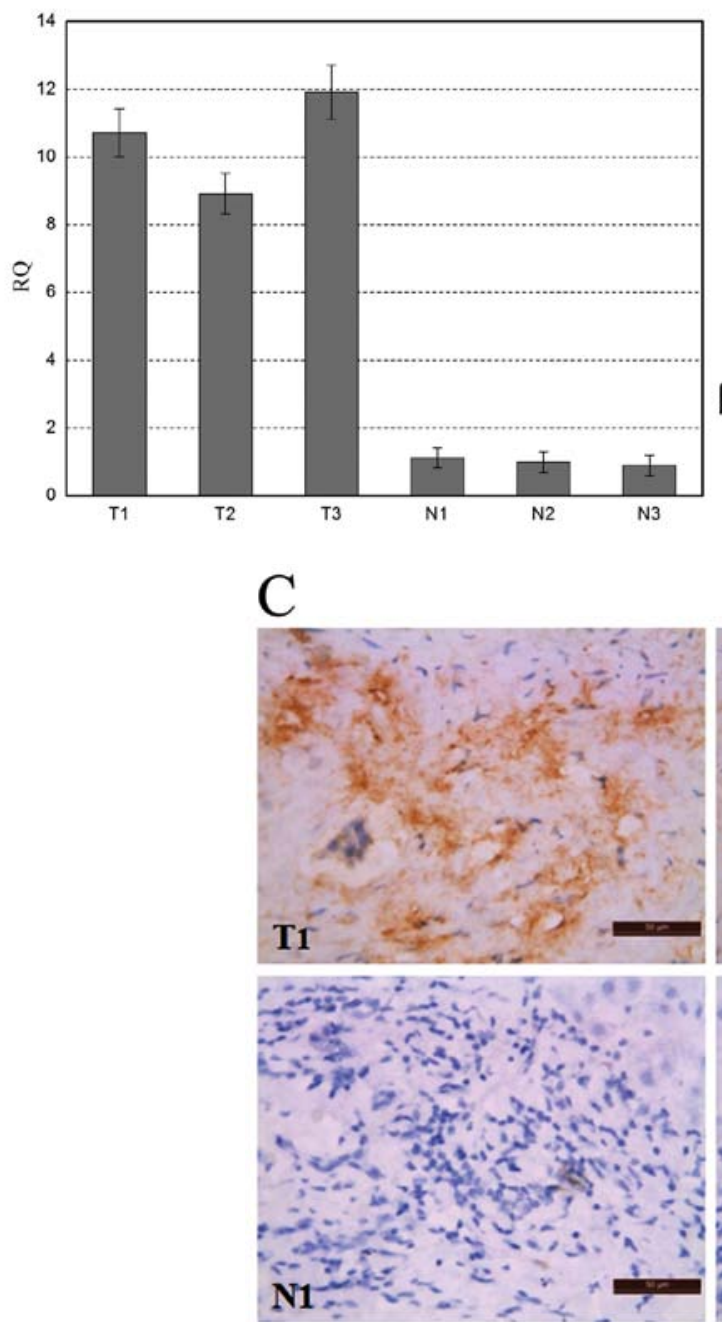

B

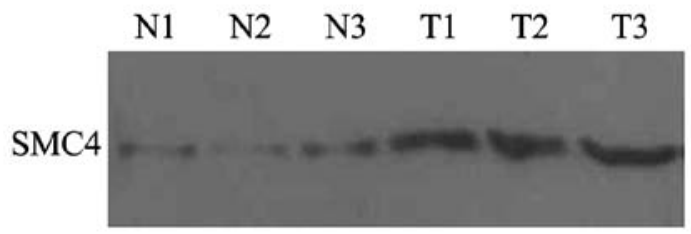

$\beta$-actin
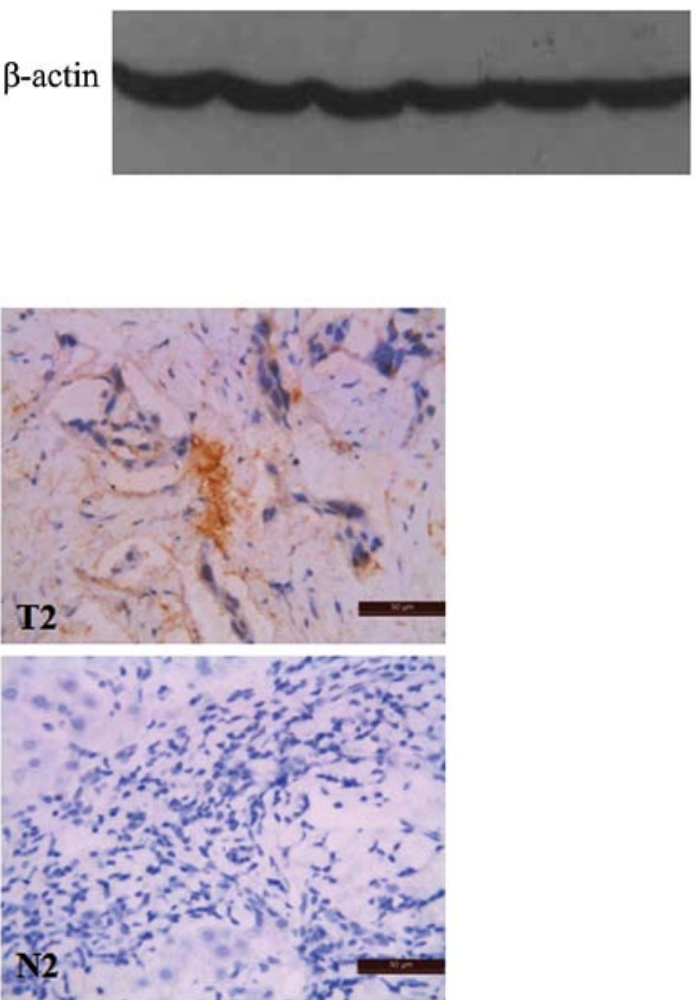

Figure 2. Analysis of SMC4 expression in hepatocellular carcinoma tissues (T) and normal liver tissues (N). (A) Real-time reverse transcription-PCR. (B) Western blotting. (C) Immunohistochemistry. Magnification x400.

A

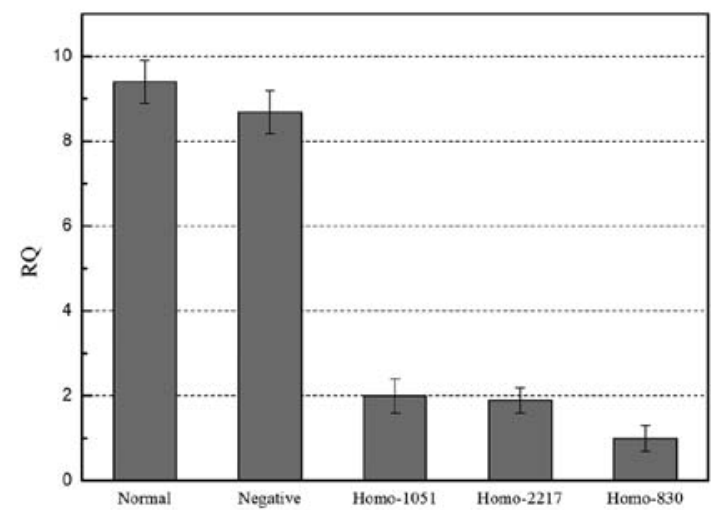

B

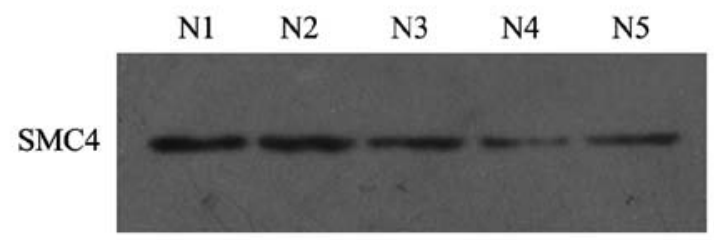

$\beta$-actin

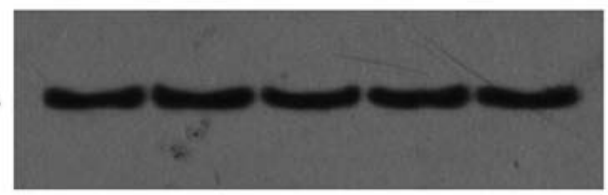

Figure 3. Effect of SMC4 siRNA on SMC4 mRNA and protein expression in a hepatocellular carcinoma cell line. (A) qRT-PCR; (B) Western blotting (N1, N2, N3, N4 and N5 were normal, negative, Homo-1051, Homo-2217 and Homo-830 respectively).

with primary liver cancer $(\mathrm{P}>0.05)$ or tumor type $(\mathrm{P}=0.170)$, indicating that $\mathrm{SMC} 4$ expression might associate with the poor survival of the patients with primary liver cancer.
Effects of SMC4 knockdown in HCC cells. Next, we designed SMC4 siRNAs and knocked down SMC4 expression in HCC $\mathrm{H}-7402$ cell line. qRT-PCR and western blot data showed that 
Table III. Association between SMC4 expression and clinicopathological data.

\begin{tabular}{|c|c|c|c|}
\hline & \multicolumn{2}{|c|}{ SMC4 expression } & \multirow[b]{2}{*}{ P-value } \\
\hline & $\begin{array}{l}\text { Strong }(\%) \\
\quad(n=52)\end{array}$ & $\begin{array}{l}\text { Weak }(\%) \\
\quad(n=20)\end{array}$ & \\
\hline \multicolumn{4}{|l|}{ Gender } \\
\hline Male & $41(75.9)$ & $13(24.1)$ & 0.228 \\
\hline Female & $11(61.1)$ & 7 (38.9) & \\
\hline \multicolumn{4}{|l|}{ Age (years) } \\
\hline$<45$ & $14(60.1)$ & $9(39.1)$ & 0.143 \\
\hline$\geq 45$ & $38(77.6)$ & $11(22.4)$ & \\
\hline \multicolumn{4}{|l|}{ Tumor size (cm) } \\
\hline$<5$ & $10(52.6)$ & $9(47.4)$ & 0.027 \\
\hline$\geq 5$ & $42(79.2)$ & $11(20.8)$ & \\
\hline \multicolumn{4}{|l|}{ Tumor type } \\
\hline $\begin{array}{l}\text { Cholangiocellular } \\
\text { carcinoma }\end{array}$ & $13(56.5)$ & $10(43.5)$ & 0.170 \\
\hline $\begin{array}{l}\text { Hepatocellular } \\
\text { carcinoma }\end{array}$ & $34(82.9)$ & $7(17.1)$ & \\
\hline Mixed type & $5(62.5)$ & $3(37.5)$ & \\
\hline \multicolumn{4}{|l|}{ Cell differentiation ${ }^{\mathrm{a}}$} \\
\hline $\mathrm{I}+\mathrm{II}$ & $8 \quad(50)$ & $8 \quad(50)$ & 0.025 \\
\hline III+IV & $44(78.6)$ & $12(21.4)$ & \\
\hline \multicolumn{4}{|l|}{ TNM stage ${ }^{b}$} \\
\hline $\mathrm{I}+\mathrm{II}$ & $7(41.2)$ & $10(58.8)$ & 0.001 \\
\hline III+IV & $45(81.8)$ & $10(18.2)$ & \\
\hline \multicolumn{4}{|l|}{ Vascular invasion } \\
\hline Negative & $18(54.5)$ & $15(45.4)$ & 0.002 \\
\hline Positive & $34(87.2)$ & $5(12.8)$ & \\
\hline
\end{tabular}

${ }^{a}$ Tumor cell differentiation was classified by The Edmondson-Steiner grade. ${ }^{\mathrm{b}}$ According to 2002 TNM Classification of Malignant Tumors by the International Union Against Cancer.

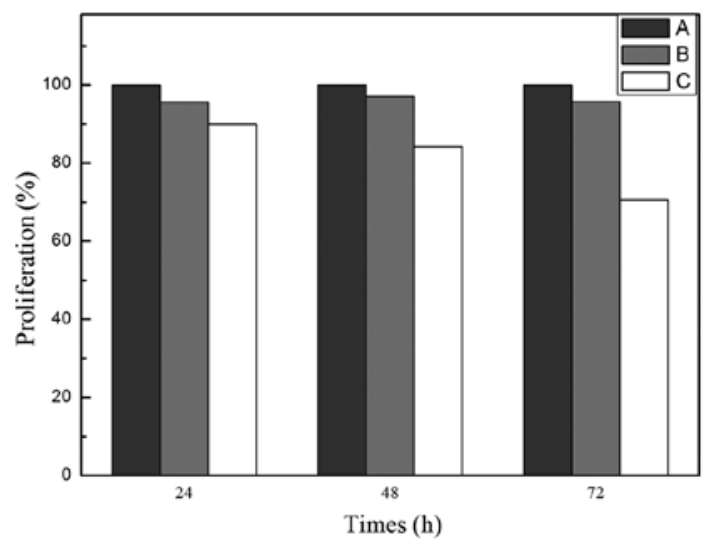

Figure 4. Effects of SMC4 knockdown in regulation of hepatocellular carcinoma cell viability. The survival rates of hepatocellular carcinoma cells at 24 , 48 and $72 \mathrm{~h}$ after SMC4 siRNA transfection were assessed by using MTT assay. three siRNA fragments were all able to knockdown SMC4 expression in $\mathrm{HCCH}-7402$ cells compared to the negative control and parental cells (Fig. 3). We then chose Homo-830 SMC4 siRNA, the most effective fragment to knockdown SMC4 expression in H-7402 cells and found that SMC4 siRNA transfection was able to reduce tumor cell viability. The survival rates of negative control SiRNA and SMC4 siRNA were 95.6 and $89.9 \%, 97.1$ and $84.2 \%, 95.7$ and $70.6 \%$, respectively, at 24, 48, and 72 h (Fig. 4). These data indicate that knockdown of SMC4 expression reduced HCC cell proliferation.

\section{Discussion}

In this study, we first detected SMC4 expression in HCC cell lines and cancer tissue specimens and found that expression of SMC4 mRNA and protein was upregulated in HCC tissues. Expression of SMC4 protein was significantly associated with tumor size, differentiation, TNM stage, and vascular invasion of primary liver cancer. Furthermore, SMC4 expression was associated with poor prognosis of patients with primary liver cancer. Next we investigated the effects of SMC4 knockdown in an HCC cell line and found that three SMC siRNA fragments were all able to knockdown SMC4 protein expression, and that use of one the best SMC4 siRNA fragment was able to reduce HCC cell viability. This study indicates the usefulness of using SMC4 protein as a tumor marker in the early detection of primary liver cancer, although further investigation is needed to verify the present data.

In the present study, we detected SMC4 expression in primary liver cancer tissue samples and found that 52 of 72 (72.2\%) paraffin-embedded cancer tissues displayed strong cytoplasm staining of SMC4 protein, but only $6(8.3 \%)$ cases had immunostaining in normal liver tissues. The difference was statistically significant, indicating the potential use of SMC4 protein as biomarker for detecting early primary liver cancer in the clinic. Furthermore, we also associated SMC4 expression with clinicopathological data from the patients, and found a significant association between SMC4 expression with tumor size, differentiation, TNM stage, and vascular invasion, indicating that overexpression of SMC4 protein is associated with a poor prognosis of the primary liver cancer patients. These findings provide evidence indicating that increased SMC4 expression is associated with development and progression of primary liver cancer, and thus could be used as an independent predictor for prognosis in patients. Our data are novel and have not been previously reported. This study provides the first link between alterations in SMC4 expression and primary liver cancer. Further studies are needed to determine the underlying mechanisms responsible for alterations in SMC4 expression in primary liver cancer, and the possible role of SMC4 in liver carcinogenesis.

We also investigated the effects of SMC4 knockdown in HCC. Our data showed that three SMC4 siRNA fragment were all able to significantly reduce SMC4 protein expression, and the Homo-830 siRNA was able to reduce HCC cell viability. These findings provide evidence that SMC4 has an obvious growth-promoting effect on HCC cells. Future studies will be needed to further investigate the role of SMC4 alterations in primary liver cancer, and the underlying molecular mechanisms. 
Indeed, SMC4 gene encodes a structural maintenance of chromosomes protein, is a subunit of condensin, and plays a central role in chromosome assembly and segregation in eukaryotic cells (32). During synchronous progression from G1 into S phase, SMC4 protein is required for normal S phase progression (33). SMC4 has been reported to play an important role in DNA replication and recombination in breast cancer (34). Altered SMC4 expression could affect chromosomal stability, and increase DNA double strand breaks and unique chromosomal rearrangements in breast epithelial cells (30).

In this study, we were for the first time able to evaluate SMC4 overexpression in primary liver cancer tissue specimens and to associate the expression with tumor size, differentiation, TNM stage, and vascular invasion in primary liver cancer tissues. Our data demonstrated that altered expression of SMC4 protein could be a novel tumor marker in the early detection of primary liver cancer and in predicting primary liver cancer progression. However, there are limitations to our present study, such as lack of Kaplan-Meier analysis of survival data and lack of data showing the mechanism responsible for SMC4 overexpression. Future study will investigate the role of SMC4 in HCC growth, invasion, and apoptosis.

\section{Acknowledgements}

We would like to thank Professor Kai-Tai Zhang of Cancer Institute and Hospital, Chinese Academy of Medical Sciences for valuable advice, Medjaden Bioscience Ltd. for editing and proofreading of the manuscript. We also specially thank Yan Li of the Department of Gastroenterology, Daping Hospital and Research Institute of Surgery for consultation.

\section{References}

1. El-Serag HB and Rudolph KL: Hepatocellular carcinoma: epidemiology and molecular carcinogenesis. Gastroenterology 132 2557-2576, 2007.

2. Ozenne V, Bouattour M, Goutté N, et al: Prospective evaluation of the management of hepatocellular carcinoma in the elderly. Dig Liver Dis 43: 1001-1005, 2011.

3. Lau WY and Lai EC: Hepatocellular carcinoma: current management and recent advances. Hepatobiliary Pancreat Dis Int 7: 237-257, 2008.

4. Hawkins MA and Dawson LA: Radiation therapy for hepatocellular carcinoma from palliation to cure. Clin Cancer Res 106 1653-1661, 2006.

5. Takayama T: Surgical treatment for hepatocellular carcinoma. Jpn J Clin Oncol 41: 447-454, 2011.

6. Cha CH, Saif MW, Yamane BH and Weber SM: Hepatocellular carcinoma: current management. Curr Probl Surg 47: 10-67, 2010.

7. Ma S, Jiao B, Liu X, et al: Approach to radiation therapy in hepatocellular carcinoma. Cancer Treat Rev 36: 157-163, 2010.

8. Wertheim JA, Petrowsky H and Saab S: Major challenges limiting liver transplantation in the United States. Am J Transplant 11: $1773-1784,2011$

9. Wiggermann P, Jung EM and Stroszczynski C: Radiofrequency ablation is a technique finished? Radiologe 52: 9-14, 2012.

10. Liapi E and Geschwind JF: Medium-sized HCC: achieving effective local tumor control with combined chemoebolization and radiofrequency ablation. Ann Surg Oncol 18: 1527-1528, 2011.

11. Smerdou C, Menne S, Hernandez-Alcoceba R and GonzalezAseguinolaza G: Gene therapy for $\mathrm{HCV} / \mathrm{HBV}$-induced hepatocellular carcinoma. Curr Opin Investig Drugs 11: 1368-1377, 2010.

12. Truty MJ and Vauthey JN: Surgical resection of high-risk hepatocellular carcinoma: patient selection, preoperative considerations, and operative technique. Ann Surg Oncol 17: 1219-1225, 2010.
13. Abelev GI, Perova SD, Khramkova NI, Postnikova ZA and Irlin IS: Production of embryonal alpha-globulin by transplantable mouse hepatomas. Transplantation 1: 174-180, 1963.

14. Lok AS, Sterling RK, Everhart JE, et al: Des- $\gamma$-carboxy prothrombin and $\alpha$-fetoprotein as biomarkers for the early detection of hepatocellular carcinoma. Gastroenterology 138: 493-502, 2010.

15. Giardina MG, Matarazzo M, Varriale A, Morante R, Napoli A and Martino R: Serum alpha-L-fucosidase: a useful marker in the diagnosis of hepatocellular carcinoma. Cancer 70: 1044$1048,1992$.

16. Ishizuka H, Nakayama T, Matsuoka S, et al: Prediction of the development of hepato-cellular carcinoma in patients with liver cirrhosis by the serial determinations of serum alpha-L-fucosidase activity. Intern Med 38: 927-931, 1999.

17. Zhu ZW, Friess H, Wang L, et al: Enhanced glypican-3 expression differentiates the majority of hepatocellular carcinomas from benign hepatic disorders. Gut 48: 558-564, 2001.

18. Allegretta $\mathrm{M}$ and Filmus $\mathrm{J}$ : Therapeutic potential of targeting glypican-3 in hepatocellular carcinoma. Anticancer Agents Med Chem 11: 543-548, 2011.

19. Oka H, Tamori A, Kuroki T, Kobayashi K and Yamamoto S: Prospective study of alpha-fetoprotein in cirrhotic patients monitored for development of hepatocellular carcinoma. Hepatology 19: 61-66, 1994.

20. Ishii M, Gama H, Chida N, et al: Simultaneous measurements of serum alpha-fetoprotein and protein induced by vitamin $\mathrm{K}$ absence for detecting hepatocellular carcinoma. Am J Gastroenterol 95: 1036-1040, 2000

21. Marrero JA, Su GL, Wei W, Emick D, Conjeevaram HS, Fontana RJ and Lok AS: Des-gamma carboxyprothrombin can differentiate hepatocellular carcinoma from nonmalignant chronic liver disease in American patients. Hepatology 37: 1114-1121, 2003.

22. Gambarin-Gelwan M, Wolf DC, Shapiro R, Schwartz ME and Min AD: Sensitivity of commonly available screening tests in detecting hepatocellular carcinoma in cirrhotic patients undergoing liver transplantation. Am J Gastroenterol 95: 1535-1538, 2000 .

23. Trevisani F, D'Intino PE, Morselli-Labate AM, et al: Serum alphafetoprotein for diagnosis of hepatocellular carcinoma in patients with chronic liver disease: influence of $\mathrm{HBsAg}$ and anti-HCV status. J Hepatol 34: 570-575, 2001.

24. Toyoda H, Kumada T, Kiriyama S, et al: Prognostic significance of simultaneous measurement of three tumor markers in patients with hepatocellular carcinoma. Clin Gastroenterol Hepatol 4: 111-117, 2006.

25. Nakamura S, Nouso K, Sakaguchi K, et al: Sensitivity and specificity of des-gamma-carboxy prothrombin for diagnosis of patients with hepatocellular carcinomas varies according to tumor size. Am J Gastroenterol 101: 2038-2043, 2006.

26. Uto H, Kanmura S, Takami Y and Tsubouchi H: Clinical proteomics for liver disease: a promising approach for discovery of novel biomarkers. Proteome Sci 8: 70, 2010.

27. Sherman M: Alphafetoprotein: an obituary. J Hepatol 34: 603-605, 2001.

28. Losada A and Hirano T: Dynamic molecular linkers of the genome: the first decade of SMC proteins. Genes Dev 19: 12691287, 2005

29. Lu KH, Patterson AP and Wang L: Selection of potential markers for epithelial ovarian cancer with gene expression arrays and recursive descent partition analysis. Clin Cancer Res 10: 3291-3300, 2004.

30. Kulawiec M, Safina A, Desouki MM, Still I, Matsui S, Bakin A and Singh KKI: Tumorigenic transformation of human breast epithelial cells induced by mitochondrial DNA depletion. Cancer Biol Ther 7: 1732-1743, 2008 .

31. Li J, Zhang N, Song LB, et al: Astrocyte elevated gene-1 is a novel prognostic marker for breast cancer progression and overall patient survival. Clin Cancer Res 14: 3319-3326, 2008.

32. Freeman L, Aragon-Alcaide L and Strunnikov A: The condensin complex governs chromosome condensation and mitotic transmission of rDNA. J Cell Biol1 49: 811-824, 2000.

33. Yu L, Peña Castillo L, Mnaimneh S, Hughes TR and Brown GW: A survey of essential gene function in the yeast cell division cycle. Mol Biol Cell1 7: 4736-4747, 2006.

34. Wang Y, Klijn JG, Zhang Y, et al: Gene-expression profiles to predict distant metastasis of lymph-node-negative primary breast cancer. Lancet 365: 671-679, 2005. 